\title{
Comment on Robert C. Merton's "On the Application of the Continuous-Time Theory of Finance to Financial Intermediation and Insurance",
}

\author{
by Stephen A. Ross*
}

When I agreed to write this comment, I was assured that the purpose of Bob Merton's address was not to break new ground, but, rather, to provide us with an assessment of the state of the field. I should have known better. Needless to say, there is so much that is new and original here that no short comment can do it justice.

Bob has done nothing less than establish a theory of financial intermediation. The engine of his theory is the drive to minimize the inevitable accumulation of transactions costs as individuals use the financial markets to intertemporally adjust their portfolios in an effort to achieve optimal time paths of holdings. Transactions costs become the production costs of manufacturing financial products. Bob's analysis makes a compelling case for both the ubiquity of transactions costs and for the push to minimize them as the underlying rationale for financial intermediation.

But, if transactions costs are to be the raison d'être for financial intermediation, how sanguine can we be about the existence of a competitive equilibrium in such models of the financial services markets? Like other cost structures that lead to combining positions and trades, transactions costs are costs that decrease with scale.

Taken at face value, the ability to pool trades and lower transactions costs and the fixed nature of the human and physical capital employed to implement the dynamic strategies that realize optimal payoff patterns for clients, lead to decreasing costs and, therefore, larger organizations. It is not too difficult to see that individual demands and supplies should be combined so as to minimize transactions costs, the difficult problem is to explain what limits concentration. In the limit why is there more than one intermediary? (A sarcastic response would be that they need someone else with whom to trade.) Bob has stressed the efficiency of pooling positions and hedging risks, and gone on to argue that technical innovations in information processing will make competing entry easier and provide a brake on concentration in the financial services industry. I agree with this, but the advantages of incumbents with the sophisticated human capital to make use of these innovations leaves the final outcome ambiguous. Let me make an argument for a different kind of countervailing force.

Presumably, on the other side we must take account of some inefficiencies that arise in big institutions. One clever suggestion - not my own - is that the limit comes from the pos-

\footnotetext{
${ }^{*}$ Yale School of Management, Yale University, New Haven CT, USA.
} 
sibility of making mistakes. Consider a world of imperfect individuals who either compute with error or communicate with each other with error. A mistake or a misjudgment that is made in one decentralized portion of an intermediary can have serious consequences for the whole, but its effects are limited. Suppose, though, that the suggestion is made that decentralization is inefficient because it leads to decision making with less than full information and to unnecessary duplication of efforts. A financial intermediary might decide to organize in a centralized fashion so that it could pool all of its positions, assess the combined risk, and pool decision making. While this may reduce the cost of hedging risks, consider what it does to the consequences of making a mistake. The costs of an error, for example, in the computation of the interest sensitivity of the asset portfolio, is magnified and the error can impact on the whole institution. While pooling makes hedging more efficient it also makes it more vulnerable to errors. At a practical level, this point is now part of the common lore in large trading houses and is often used by them to justify not keeping a common "book" for all the trading desks.

The final resolution of the tradeoff between the efficiency of maintaining an overall asset/liability policy and the error reducing virtues of decentralization and redundancy depends to some extent on the exact technology of transactions costs. Bob takes a step towards clarifying this by evaluating the computational economies that are achieved from aggregating risk exposures in terms of the $n$ underlying assets form which $m>n$ products are derived. But, an even greater simplification is possible.

In the fixed income markets, for example, we have thousands of products and, arguably, thousands of underlying assets as well. Is a three month bond to be included in the risk management matrix of customer-product liabilities beside a two month and a four month, not to mention the 13 and the 11 week bonds?

Empirical analysis suggests that for practical purposes just three factors, at most, are sufficient to determine the risk of holding (default free) fixed income instruments. The first might be thought of as arising from movements in the level of interest rates, the second from twists in the yield curve, and the third from concavity or changes in volatility. This reduces the problem of hedging and risk management from that of controlling the exposures to the thousands of underlying assets to that of controlling exposures to three factors. As a matter of theory, this is the proper underlying basis space in which to work, and as a matter of practice it is even more appropriate. Of course, if we really do believe that markets are complete and that all individuals have von-Neumann Morgenstern utility functions then a further reduction to a single consumption aggrgate is possible. But the underlying assumptions seem heroic and the empirical analysis of this theory has not been very kind.

Perhaps, though, the most significant limitation of the transactions costs approach lies in what it omits or hopes to treat as implicit. Bob, of course recognizes that transactions costs are only names for a broader class of issues and costs. To a large extent, then, the success of a transactions cost based approach to financial intermediation turns on its ability to adequately encompass these other costs. In particular, it must take account of marketing costs. But, are marketing costs the same as transactions costs? I don't think so.

For one thing, marketing costs are endogenous to a magnitude that transactions costs are not. While, it seems entirely appropriate to take a partial equilibrium perspective and assume that there is some parameter that reflects the costs of executing a trade, even 
though that parameter may be a function of prices and of trading volume and of asymmetric information, this is far less satisfactory for marketing costs. The cost of marketing depends on such variables as the products selected, the capital decisions that are made to develop and maintain distribution networks, and on the very customers approached. These considerations are difficult to fit into the particular technical framework employed by Bob.

In particular, an analysis of marketing should take account of the possibilities for moral hazard and adverse selection and of their role in defining financial institutions in the presence of asymmetric information. But this is not the approach in models where the driving force determining the demand for financial products is the retail investor in a complete market. The use of the log utility approach - indeed of any von-Neuman Morgenstern utility function - to determine demand in a complete market, assumes away such issues. It is now well appreciated that separable, state independent utility is a powerful assumption on preferences and more so in complete markets. This places a greater burden on justifying its use when we leave Arrow-Debreu retail markets with individual investors and move on to markets with institutions and asymmetric information. We must now ask who acts as though they have such utility functions and how customers can actually validate that institutions will provide promised payoffs.

The world we must understand, then, is one in which the customer needs as much information to evaluate the product as he or she needs to create it for themselves in the marketplace. While there is much to be said for the argument that pooling of trades by intermediaries makes it possible to reduce costs and achieve what no individual could do for themselves, it begs the question of who is watching the shop and seeing to it that the customer is getting what they think they bought. This, again, focuses attention on the central role of marketing in explaining financial intermediation.

But now we are getting ahead of the story of this paper and by doing so we are emphasizing its importance. Any future discussions of financial intermediation will have to deal with this analysis of transactions costs. In an important sense, Bob has provided us with the neoclassical formulation of a theory of financial intermediation, and it is surely prior to the delicate discussions of the exact role of information. Before closing, though, I would not want the reader to think that this is merely a paper for the cognoscenti to read. Those who prefer their economics to focus on policies and not on models will find much here to excite them.

I particularly liked two points. First, that the option pricing technology itself tends to blur the lines among different products and services. When coupled with the existence of markets that imply easy entry into the industry, the prediction is that the lines between institutions will become less distinct. Insurance companies that provide portfolio management services are only a semantic breath away from portfolio managers who provide insurance (or, assurance, to be exact). Second, Bob makes a wonderful analogy between trains that use rails, and financial institutions that use the financial infrastructure. Absent a charge, a speed limit is a way to solve the public good problem of not overusing the track, but too heavy handed an application can lose the benefits of high speed trains and serve as a disincentive to their development. Furthermore, the speed limit is not usually a better alternative to upgrading the infrastructure. While I am not sure I want to ride this train to its final destination in our financial markets, this metaphor alone makes the paper worth the read. 